\title{
Sub-Surface Method of Irrigation- Clay Pipe Irrigation System
}

\author{
Dr. Balkrishna Sopan Bhople, Kunal Adhikary, Dr. Anil Kumar, \\ Amrinder Singh, Gurbir Singh \\ Department of Agriculture, School of Agriculture, Lovely Professional University, Punjab 144411, India
}

\begin{abstract}
As we know that earth surface is covered with $75 \%$ of water and out of that only $2.5 \%$ of water is fresh, from that we use $70 \%$ of fresh water for irrigation. From research we came to know that maximum amount of water is getting loss in agricultural field, water withdrawal rate in 2050 is $50 \%$ in developing countries like India. To solve the problem of water scarcity, we need proper water management and water efficient irrigation system.Clay pipe irrigation system is the one of the most water efficient, eco-friendly and cheapest method. In this system we use clay pipes which are buried into the sub surface of the soil and by the capillary action water sweeps out from the unglazed wall of the clay pipes due to which soil get moisturize. By this method only optimum amount of water is provided to the crops.As in this system there is no water logging on the soil surface, hence we can also solve the weed management issue and proper salt distribution in the soil. This method is so easy to manage as no high-tech work is required and it is eco-friendly also because no toxic and residual waste is used in this system. Initial cost for this system is 40,000 rupee per acre (aprox) and it is multi seasonal (this system can be use for more than 10 seasons). This is suitable for those regions where the rainfall is less than $500 \mathrm{~mm}$ per year. Clay pipes will have proper composition of clay and ash so that it has proper water permeability and maintained porosity. All the fibrous root crops like fibrous root vegetables can be practice by this method and they will give good yield and quality. Water saving rate from this method is 50$70 \%$ in vegetable crops. It is more viable in intensive agriculture.
\end{abstract}

\section{Introduction}

Subsurface irrigation involves the application of irrigation water beneath the soil surface. It is usually carried out by burying the medium used to convey the water at some depth below the soil surface. Some media used to convey water for subsurface irrigation include pots, pitchers, porous clay pipes, perforated pipes and plastic drip lines with emitters. As water moves in the buried medium, it leaks or permeates into the soil, thus wetting and raising the moisture content of the soil. Subsurface method of irrigation is becoming increasingly common especially in the developed nations as a way of watering and fertilizing greenhouse crops. It is known to be very effective in management of irrigation water because of high irrigation uniformity and water use efficiency in a number of different cropping systems by supplying a low volume of water to the root zones of crops (Bainbridge, 2001; Ashrafi et al., 2002). Power (1985), Sheikh and Shah (1983), Batchelor et al. (1996), Hagazi (1998) and Bainbridge (2001) have reported high water use efficiency (i.e., high crop production per amount of water applied) for subsurface irrigation method. Subsurface method of water application is increasingly being used for the irrigation of corn, fruits and vegetables (Camp, 1998; Singh et al., 2006). One noted improvement on the traditional method of subsurface irrigation is the use of porous clay pipes (Siyal and Skaggs, 2009). The clay pipes consist of baked short length pipes $(25$ to $50 \mathrm{~cm})$ made from clay which are joined together or lay end to end to form long tubes of desired length. The pipes are buried in the soil, and water is supplied continuously to these pipes from a point source. At one end, an elbow fitting is attached and an upright section of pipe installed. Water is poured into the porous pipe through the upright pipe. The water seeps into the root zones through the joints between the individual pipes, or through the pipe walls if the pipe surface is not glazed. As water seeps out of the porous wall of the pipe it creates a wetting front along the entire length of the lateral. This method irrigation has been used in some arid and semi-arid regions of the world with a significant success (Ashrafi et al., 2002; Qiasheng et al., 2007). It has been found suitable for crops grown in row such as vegetables and trees (Ashrafi et al., 2002). Siyal (2008) computed the water used for the growing of turnip (an edible root vegetable) using clay pipes and compared with water needed by turnip when irrigated with flood irrigation method, and found out that the clay pipe method saved more water than the flood irrigation method for sandy-loam soil. The turnip production obtained was 11 ton/ha for the clay pipe method which is about $20 \%$ more than that obtained with application of conventional flood irrigation. Siyal et al. (2011) also reported that with the clay pipe irrigation method, water saving up to $80 \%$ were achieved compared to that of surface irrigation methods. Moreover, yield of vegetables (okra, eggplant and turnip) irrigated with the system were 5 to $16 \%$ more than the normal production obtained with surface irrigation methods. The ITDG (2002) technical briefing also reported that though clay pipes were laborious to fill by women who used them to raise 
vegetables, it was much more cost effective as the vegetables needed to be watered only a week instead of 3-4 times for surface watering, thus reducing watering by $50 \%$.

\section{Fabrication and field evaluation of clay pipe}

This study was carried out in the Department of Agricultural Engineering, Ahmadu Bello University Zaria. The University lies in Latitude 11011' $\mathrm{N}$ and Longitude 7035'E, at $686 \mathrm{~m}$ above sea level (Henry 2013). They used three types of clay pipes which were fabricated. Type A was made from $100 \%$ pure clay, Type B was $95 \%$ clay and $5 \%$ fine sand, and Type $\mathrm{C}$ was $90 \%$ clay, $5 \%$ fine sand and $5 \%$ sawdust. For each Type, three pipes and one elbow were fabricated. The length of each pipe was $50 \mathrm{~cm}$ long. The thickness of each pipe was $2.5 \mathrm{~cm}$ with regular inner and outer diameters of $7.5 \mathrm{~cm}$ and $10 \mathrm{~cm}$, respectively. At one end of each pipe, a coupling head was made. The inner and outer dimensions of the coupling head were $10 \mathrm{~cm}$ and $12.5 \mathrm{~cm}$, respectively. This was made to allow for fitting of the other end of the pipe into the coupling head of the other pipe. The three pipes of each type gave a total length of $1.5 \mathrm{~cm}$ long when coupled together. The elbow of each Type was $33 \mathrm{~cm}$ long and $26.5 \mathrm{~cm}$ high with $10 \mathrm{~cm}$ radius. The elbow was also coupled to one end of the pipe length, and upon installation in the soil, the height of the elbow protrudes above the soil surface by $5 \mathrm{~cm}$. Through the protruded opening, the pipes filled with water. Since the pipe fitted at the end of pipe length had a close end, the entire pipe length can hold water of about 5.5 liters at a time.

Henry(2013) set up the experimental plot as three seedbeds of $0.6 \mathrm{~m} \times 2.0 \mathrm{~m}(1.2 \mathrm{~m} 2)$ each were tilled and excavated to a depth of $25 \mathrm{~cm}$ from the soil surface at the center along the bed length for the purpose of installing the fabricated clay pipes. Henry (2013) also reported the experimental soil physical characters and the seepage rate of the different pipe. Also checked the soil wetting pattern at the different distance.

Henry (2013)

\begin{tabular}{|c|c|c|}
\hline Clay Pipe Type & $\begin{array}{c}\text { Seepage Rate } \\
\text { (cm3/hr) }\end{array}$ & $\begin{array}{c}\text { Hydraulic } \\
\text { Conductivity } \\
\text { Ks (cm/hr) }\end{array}$ \\
\hline A (100\%clay) & 6130 & 2.07 \\
\hline B (95\%clay+5\%sand) & 9100 & 3.08 \\
\hline $\begin{array}{c}\text { C (90\% clay+ } \\
\text { 5\%sand+5\%saw dust) }\end{array}$ & 14200 & 4.80 \\
\hline
\end{tabular}

Another work was done by the Sindh Agricultural University on crop production and water use efficiency under sub-surface clay pipe irrigation system (A. A. Siyal, A. G. Siyal and M. Y. Hasini 2011 ). Clay pipe segments, each of length $40 \mathrm{~cm}$, were joined together and then buried in 25 trenches (laterals), each of $20 \mathrm{~m}$ length and $0.43 \mathrm{~m}$ depth. Water was supplied from an overhead tank to all the laterals via main line. When soil above laterals became visibly wet, soil moisture distribution within root zone was determined and simulated with HYDRUS-2D. Okra, Eggplant and turnip were then sown separately on moist soil above laterals. These vegetables were irrigated until harvest through buried clay pipe laterals. The experimental results revealed that with this method water savings up to $80 \%$ were achieved compared to that of surface irrigation methods. Also yield of vegetables irrigated with this system was 5 to $16 \%$ more than the normal production obtained with surface irrigation methods.

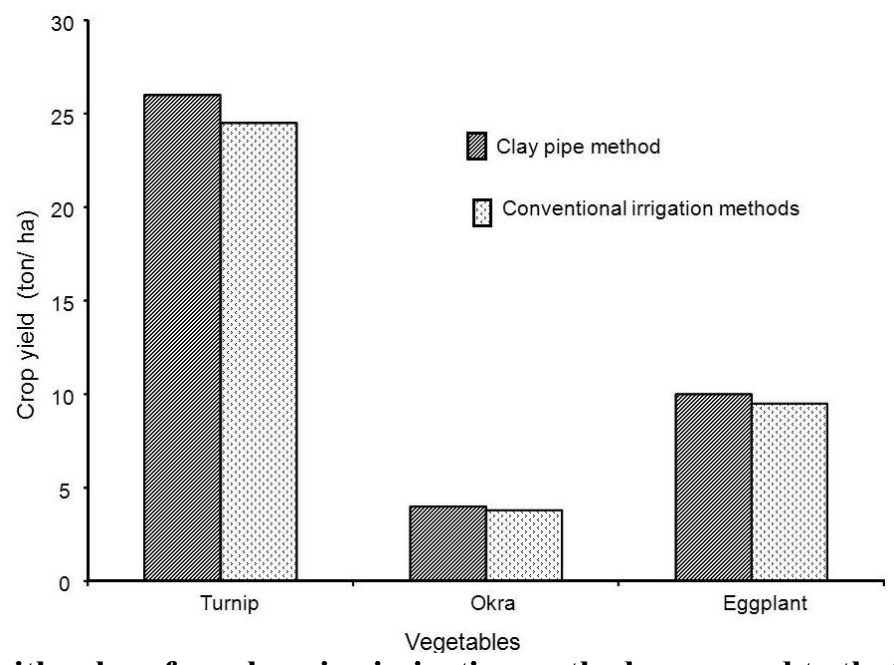

Crop yield obtained with subsurface clay pipe irrigation method compared to that of with conventional surface flooding method. (A. A. Siyal, A. G. Siyal and M. Y. Hasini 2011 ). 


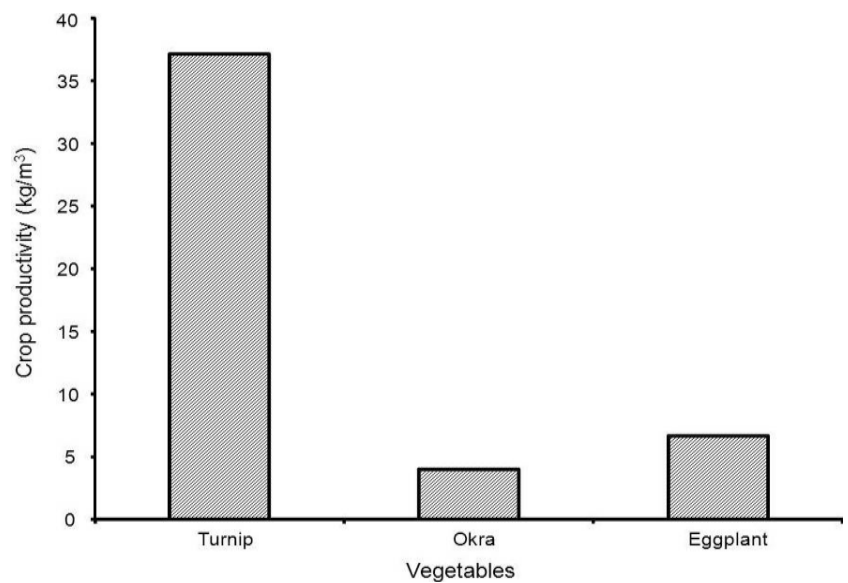

Crop productivity of various vegetables with subsurface clay pipe irrigation method. (A. A. Siyal, A. G. Siyal and M. Y. Hasini 2011 ).

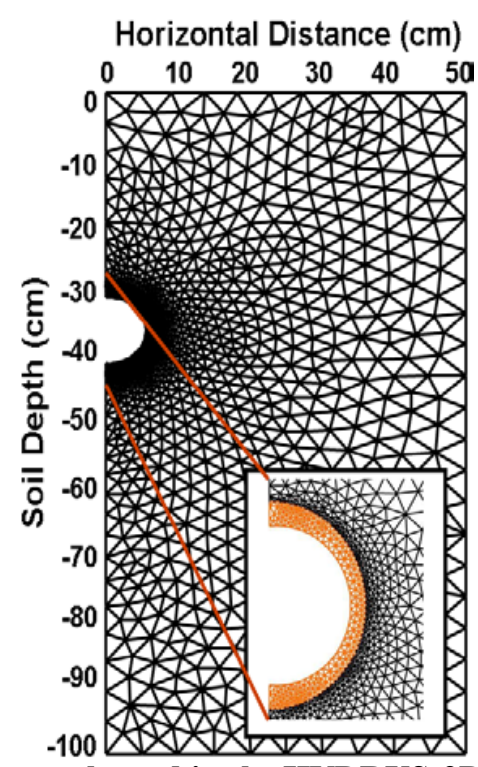

Typical geometry and finite element mesh used in the HYDRUS-2D simulations(A. A. Siyal, A. G. Siyal and M. Y. Hasini 2011 ).

\section{Futuristic aspects of clay pipe irrigation system:}

As it has been found from the previous study that clay pipe irrigation system is a water efficient method of irrigation which will prove helpful in the arid or the semi-arid region of the country. Most of the work has been done on the fabrication of the clay pipe, its seepage rate and its designing. As per the reference of (A. A. Siyal, A. G. Siyal and M. Y. Hasini 2011 ),we found that vegetables crops can be efficiently grown by this method and $80 \%$ of water can be save as compared to the traditional method of irrigation. As a country like India which has a culture of pottery also initiate the employment in this field and generate the income.

We like to do more work on the composition of the clay for pipe so that we can make it more strengthen and porous by the help of additives and practically use to cultivate the more crops on the arid and semi arid regions by this method and compare their growth rate, total water requirement and the comparable study of traditional and this method on such water scares region.

\section{References}

[1]. Siyal, A. A. 2008. Water-saving clay pipe irrigation system. Daily Dawn.

[2]. http://www.dawn.com/2008/12/22/ebr6.htm.

[3]. Siyal, A. A., M. Th. van Genuchten and T. H. Skaggs. 2009. Performance of pitcher irrigation systems. Soil Science, 174 (6): $312-$ 320 .

[4]. Siyal, A.A., A.G. Siyal, and M.Y. Hasini. 2011. "Crop Production and Water Use Efficiency under Subsurface Porous Clay Pipe Irrigation”. Pakistan J. Agric. Eng'g., Vet. Sc. 27(1):39-50.

[5]. Hydraulic Characteristics of Porous Clay Pipes for Subsurface Irrigation.

[6]. Henry E. Igbadun, Ph.D.* and Japheth Barnabas, B.Eng. 